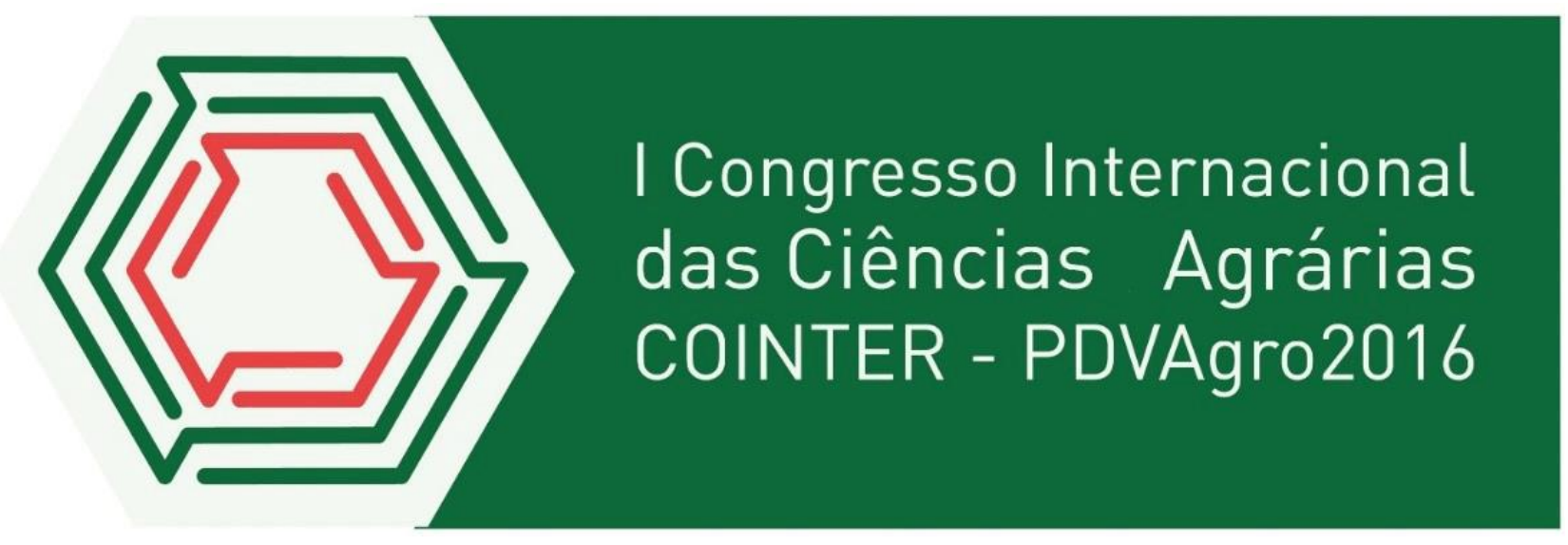

\title{
CONHECENDO O SOLO E COLORINDO O SEMIÁRIDO PARAIBANO ATRAVÉZ DA GEOTINTA NO CONTEXTO ESCOLAR
}

Apresentação: Relato de Experiência

Marcilene Santos Silva ${ }^{1}$; Rayana Vanessa Alves Silva ${ }^{2}$; Luana Fernandes Melo ${ }^{3}$; Maria da Piedade Pê de Nero ${ }^{4}$; Albertina Maria Ribeiro Brito de Araújo ${ }^{5}$

\section{Introdução}

É notório que na maioria dos municípios brasileiros a educação deixa muitas lacunas a preencher, principalmente no que se refere a metodologias e didáticas diferenciadas e contextualizadas à realidade do estudante. A educação ambiental, assim como a agroecologia e a Educação Contextualizada para Convivência com o Semiárido geralmente não são discutidas em contextos escolares, embora sejam temas de grande relevância para a formação de um sujeito crítico, ético e consciente com as questões ambientais.

Esse trabalho buscou enfatizar a formação crítica de educandos da rede pública de ensino, em uma perspectiva de educação popular contextualizada, de resgate e valorização da cultura camponesa, dando ênfase as especificidades ambientais da região semiárida a qual os sujeitos envolvidos estavam inseridos, a sustentabilidade local e a importância da conservação e características dos solos da região.

\section{Relato de Experiência}

A experiência foi realizada na Escola Municipal de Ensino Fundamental João Soares da Costa, localizada na comunidade de Cacimba da Várzea, Solânea-PB, por meio do projeto de extensão intitulado "Agroecologia e Educação para Convivência com o Semiárido" que em seus objetivos busca realizar ações socioambientais e culturais, com estudantes de escolas públicas em ambiente escolar, sobre a importância da agroecologia, da educação ambiental e da educação contextualizada para a convivência com o Semiárido Brasileiro.

Este trabalho deteve apoio da equipe gestora da escola, colaboradores do projeto Agroecologia e Educação para Convivência com o Semiárido e a Rede de Educação do Semiárido

\footnotetext{
${ }^{1}$ Licenciatura em Ciências Agrarias, CCHSA/UFPB, Marcilene-1995@ hotmail.com

2 Pós-graduação em Ciências Agrárias “Agroecologia”, UFPB/CCHSA, rayana.vanessa@ hotmail.com

${ }^{3}$ Pós-graduação em Ciências Agrárias “Agroecologia”, UFPB/CCHSA, luanaagroecologia@ hotmail.com

${ }^{4}$ Técnico Agrícola com habilitação em Agropecuária, CAVN/UFPB

${ }^{5}$ Docente, UFPB/CCHSA, albertinari@ hotmail.com
} 
Brasileiro (RESAB), que é um espaço de articulação política regional da sociedade organizada, congregando educadores/as e instituições Governamentais e Não-Governamentais, que atuam na área de Educação no Semiárido Brasileiro, com o intuito de elaborar propostas de políticas públicas no campo educacional e desenvolver ações que possam contribuir com a melhoria da qualidade do ensino e do sistema educacional do semiárido brasileiro.

A atividade foi desenvolvida de maneira holística, dinâmica e dialógica, por meio do mapeamento de atividades interdisciplinares com ênfase na agroecologia, na educação ambiental e em estratégias de convivência com o Semiárido Brasileiro. Visto a necessidade da priorização da temática: uso e conservação dos solos. Inicialmente, foi realizada uma sondagem e reflexão sobre a origem, formação, conceitos incluindo importância, propriedades, formas de contaminação, formas preservação e uso na agricultura, dando ênfase as caraterísticas do Semiárido Brasileiro (SAB), foram utilizados recursos áudio visuais e expositivos, dinâmicas de grupo, músicas e brincadeiras contextualizadas, acerca do tema proposto. Em seguida para a observação das características e cores dos solos, foi realizada um passeio aos arredores da escola e a atividade prática da geotinta, que é uma tinta ecológica a base de solos de diferentes cores, não contém componentes nocivos à saúde, além disso tem baixo custo, e baixo impacto ambiental. Segundo Coaracy (2015, p. 9): "A geotinta é uma forma simples e sustentável de melhorar a aparência dos ambientes internos, externos e dos objetos."

De acordo com Medeiros (2011, p. 2): “A educação ambiental nas escolas contribui para a formação de cidadãos conscientes, aptos para decidirem e atuarem na realidade socioambiental de um modo comprometido com a vida, com o bem-estar de cada um e da sociedade."

\section{Considerações}

Trabalhar de forma contextualizada com educandos de escolas públicas do campo e filhos de agricultores familiares, nos possibilitou grandes reflexões à respeito das potencialidades e desafios enfrentados por eles, tendo em vista que os mesmos são os construtores de suas identidades e histórias, tornando bem mais produtivo um diálogo e construção de conhecimentos de ambas as partes. Pode-se observar um crescente aumento de interesse dos estudantes pela temática trabalhada, já que dificilmente se discute na escola de uma maneira contextualizada e interativa, com isso, por meio da extensão buscou-se uma melhor valorização e otimização dos conhecimentos dos educandos, tentando sempre implica-los no processo de ensino e de aprendizagem.

\section{Referências}

COARACY, T. N. Agroecologia e permacultura a favor do campo acadêmico, comunidade rural e urbana. Trabalho de Conclusão de Curso, Lagoa Seca- PB, 2015.

MEDEIROS, A. B. et al. A importância da educação ambiental na escola nas séries iniciais. Revista Faculdade Montes Belos, v. 4, n. 1, 2011, p. 17. 